\title{
DE LA APLICACIÓN SUPLETORIA DEL CÓDIGO DEL TRABAJO A LOS PROFESIONALES DE LA EDUCACIÓN DEL SECTOR MUNICIPAL: LO FAVORABLE U ODIOSO DE UNA DISPOSICIÓN NO SE DEBE TOMAR EN CUENTA PARA AMPLIAR O RESTRINGIR SU INTERPRETACIÓN (COMENTARIO A SENTENCIA DE LA EXCMA. CORTE SUPREMA)
}

\author{
IVONNE PONCE HEINSOHN* \\ Universidad Austral de Chile
}

Santiago, tres de agosto de dos mil doce.

Dando cumplimiento a lo dispuesto en el artículo 483-C, inciso segundo, del Código del Trabajo, se dicta la sentencia de remplazo que sigue en unificación de jurisprudencia.

\section{VISTOS:}

Se reproduce los considerandos primero a tercero y décimo quinto de la sentencia de nulidad de veintitrés de septiembre de dos mil once, dictada por la Corte de Apelaciones de San Miguel, a fojas 148 y siguientes.

Y teniendo presente:

PRIMERO: Que el demandado dedujo recurso de nulidad sustentado en la causal del artículo 477 del Código del Trabajo, sosteniendo que la sentencia recurrida se dictó con infracción de los artículos 485, 486 y 489 del Código del Trabajo en relación con el artículo 42 de la Ley $\mathrm{N}^{\circ} 19.070$. Afirma que la demandada no ha vulnerado derecho alguno de la trabajadora que justifique la deducción de una acción de tutela, agregando que es la actora quien utilizando la institución del despido indirecto que no tiene reconocimiento en el Estatuto Docente, ha renunciado voluntariamente a su trabajo y que éste no puede crear o inventar nuevas causales de despido distintas a las ya consagradas en forma expresa y taxativa por el artículo 72 de la Ley $\mathrm{N}^{\circ} 19.070$. Manifiesta que no procede que la actora cuestione su destinación a un nuevo establecimiento educacional, en atención a que la Corporación Municipal ejerció la prerrogativa legal consagrada en el artículo 42 de la Ley antes señalada, la que no fue cuestionada en su legalidad. La vulneración del artículo 486 del Código del Trabajo se produce por el rechazo de la excepción de caducidad, a pesar de que los supuestos hechos relatados por la actora -de la gravedad exigida en el artículo 489 del Código del Trabajo-, habrían ocurrido con anterioridad a los seis meses previstos en la norma en estudio.

Profesora de la Facultad de Ciencias Jurídicas y Sociales de la Universidad Austral de Chile. 
En un segundo capítulo del recurso de nulidad se denuncia la infracción de los artículos 38 de la Constitución Política de la República; 15 de la Ley $N^{\circ} 18.575$; 4, 13, 23, $1567 \mathrm{~N}^{\circ} 1$ y 1698 del Código Civil; 1, 12, 160, 162, 171, del Código del Trabajo; 1, 22, 25, 42, 71, 72, 77 y 87 del Estatuto Docente; y 144 del Código de Procedimiento Civil. La vulneración de los artículos $4^{\circ}$ y 13 del Código Civil se produce en relación con los artículos 71 y 72 del Estatuto Docente y $1^{\circ}$ y 171 del Código del Trabajo, en atención a que se extiende a un profesional de la educación una normativa relativa al término de la relación laboral, que no corresponde, vulnerando el principio de especialidad, ya que el Código del Trabajo tiene aplicación supletoria, lo que no ocurre en la especie en atención a que el Estatuto Docente trata de la terminación del contrato de trabajo y establece taxativamente causales exclusivas y excluyentes al respecto. Al efecto, debe tenerse presente lo dispuesto en el artículo 23 del Código Civil en el sentido que lo favorable u odioso de una disposición no se tomará en cuenta para ampliar o restringir su interpretación y que la interpretación que debe darse a la ley se determinará por su genuino sentido. Agrega que la sentencia dejó de aplicar los artículos 38 de la Constitución Política de la República y 18 de la Ley 18.575, al olvidar que los funcionarios de la administración del Estado se rigen por sus propios estatutos. El quebrantamiento de los artículos 162 y 171 del Código del Trabajo se produce al aplicar la sanción propia de la nulidad del despido por no pago de cotizaciones previsionales cuando no procede, ya que el término de la relación laboral no se produjo por la voluntad del demandado; se contravinieron los artículos 1567 Nº 1 y 1698 del Código Civil, al no dar por pagadas las cotizaciones previsionales, a pesar de haberse acreditado su completa solución. La infracción de los artículos 22, 25 y 42 del Estatuto Docente, en relación con el artículo 12 del Código del Trabajo, se produce al olvidar las facultades de la demandada para trasladar de establecimiento educacional a la actora. Manifiesta que se quebrantaron los artículos 72 y 75 de la Ley $\mathrm{N}^{\circ} 19.070$, al desconocer el juez del grado la existencia de un contrato a plazo celebrado con la actora que por su vencimiento justifica la reducción de horas de trabajo. Termina el capítulo señalando que no procede la indemnización establecida en el artículo 87 del Estatuto Docente, por no concurrir al respecto los requisitos legales.

En subsidio, invoca la causal de nulidad establecida en el artículo 478 letra b) del Código del Trabajo, por haber sido dictada la sentencia con infracción manifiesta de las normas de la sana crítica, desatendiendo el artículo 456 del Código del Trabajo al momento de dar por establecidos los hechos alegados por la actora como fundamento de su acción.

Termina señalando la manera en que los hechos denunciados influyeron sustancialmente en lo dispositivo del fallo.

CUARTO: Que para una apropiada solución de la controversia, es necesario determinar el régimen jurídico a que estaba sujeta la actora en el desempeño de sus funciones como profesional de la educación. Al efecto, corresponde considerar lo que previene el artículo $1^{\circ}$ del Estatuto Docente aprobado por la Ley No 19.070, cuyo texto refundido se contiene en el Decreto con Fuerza de Ley No 1, de 1996, acerca de que "quedarán afectos al presente Estatuto los profesionales de la educación que prestan servicios en los establecimientos de educación básica y media, de administración municipal o particular reconocida oficialmente" y lo que, a su turno, señala el artículo 19 del Párrafo I del Título III del mismo cuerpo legal, en orden a que "el presente Título se aplicará a los profesionales de la educación que 
desempeñen funciones en los establecimientos educacionales del sector municipal integrando la respectiva dotación docente”.

QUINTO: Que, por su parte, el artículo 71 del mencionado Decreto con Fuerza de Ley declara que "los profesionales de la educación que se desempeñan en el sector municipal se regirán por las normas de este Estatuto de la profesión docente y supletoriamente por las del Código del Trabajo y sus leyes complementarias". Esta regla concuerda con lo que preceptúan los incisos segundo y tercero del artículo $1^{\circ}$ del Código Laboral, en orden a que sus "normas no se aplicarán, a los funcionarios de la Administración del Estado centralizada y descentralizada, del Congreso Nacional y del Poder Judicial ni a los trabajadores de las empresas o instituciones del Estado o de aquellas en que éste tenga aportes, participación o representación, siempre que dichos funcionarios o trabajadores se encuentren sometidos por ley a un estatuto especial" y a que "con todo, los trabajadores de las entidades señaladas en el inciso precedente se sujetarán a las normas de este Código, en los aspectos o materias no regulados en sus respectivos estatutos, siempre que ellas no fueren contrarias a estos últimos".

SEXTO: Que de las disposiciones transcritas en los considerandos que preceden, resulta que la demandante en sus relaciones con la Corporación demandada se hallaba especialmente sometida al Estatuto Docente y, en forma supletoria, a las disposiciones del Código del Trabajo, pero solo en los asuntos no regulados por dicho Estatuto y en la medida en que las normas del Código Laboral no fueran contrarias a las de esa normativa especial.

SÉPTIMO: Que el término de la relación laboral de los Profesionales de la Educación se sujeta a las disposiciones del Párrafo VII del mismo Estatuto, cuyo artículo 72 señala taxativamente las causales por las cuales se puede dejar de pertenecer a la dotación docente municipal, sin que se contemple en ésta el autodespido del trabajador.

OCTAVO: Que, por otra parte, la letra g) del aludido artículo 72 indica que los Profesionales de la Educación también pueden dejar de integrar a una dotación docente municipal por la "supresión de las horas que sirvan" y, a su vez, el artículo 73 del mismo texto legal se refiere a la forma cómo debe hacerse efectiva esta causal y en su inciso quinto dispone que los titulares tendrán derecho a una indemnización de cargo del empleador, por los años servidos, en los términos en que allí se regula. Así también, el artículo 77 del citado Estatuto Docente declara que si la adecuación de una dotación docente por aplicación de su artículo 22 representa una supresión parcial de horas, los profesionales de la educación de carácter titular que sean afectados, tendrán derecho a recibir una indemnización parcial, en proporción al número de horas que dejen de desempeñar.

NOVENO: Que de las normas estatutarias antes relacionadas resulta que los profesionales de la educación municipal dejan de pertenecer a una dotación docente solo en virtud de las causales establecidas en el artículo 72 antes referido, y no por las disposiciones del artículo 171 del Código del Trabajo y que únicamente en virtud de la supresión total o parcial de las horas de clases que sirvan en calidad de titulares, pueden percibir una indemnización por el cese de sus funciones, de modo que en la medida que la actora no expiró en su empleo en virtud de esa causal, no tiene derecho a impetrar ese beneficio.

DÉCIMO: Que, en consecuencia, las normas del Código Laboral relativas al contrato de trabajo, al aviso de la terminación del contrato laboral, al autodespido, a las indemniza- 
ciones sustitutivas de dicho aviso y por años de servicios que encierran sus artículos 7, 8, $160,161,162,163$ y 171, no pueden recibir aplicación supletoria en el caso de la actora, ya que, según se ha anotado, el Estatuto Docente establece su propia regulación en torno a las causales de expiración en los cargos de titulares y a los beneficios a que puede dar lugar el cese de funciones y sus disposiciones rigen con preferencia a quienes integran una dotación docente, excluyendo el imperio del derecho laboral común en esos asuntos, al tenor de lo preceptuado tanto en el artículo $71 \mathrm{del}$ mismo Estatuto Docente como en los incisos segundo y tercero del artículo $1^{\circ}$ del Código del Trabajo, sin perjuicio de considerarse además el artículo 13 del Código Civil.

UNDÉCIMO: Que de lo razonado en el considerando que antecede resulta inconcuso que tampoco se aplica a la demandante la norma del inciso séptimo del artículo 162 del Código del Trabajo, en cuanto establece la nulidad del despido por no pago de cotizaciones previsionales, ya que la mencionada sanción está establecida en el referido Código dentro de las normas de terminación del contrato de trabajo y, como se dijo, es el Estatuto Docente el que establece su propia regulación en torno a las causales de expiración en los cargos de titulares y a los beneficios y sanciones a que puede dar lugar el cese de funciones y sus disposiciones rigen con preferencia a quienes integran una dotación docente, excluyendo el imperio del derecho laboral común en esos asuntos.

DUODÉCIMO: Que sin perjuicio de lo anterior y solo para los efectos del presente recurso de unificación de jurisprudencia, de conformidad con lo dispuesto en los artículos 483 y 483-C del Código del Trabajo, en el supuesto de haber resultado aplicables las normas del Código Laboral, ante la constatación de distintas interpretaciones sostenidas en fallos firmes emanados de Tribunales Superiores de Justicia, respecto de la procedencia de la sanción establecida en el inciso séptimo del artículo 162 del Código del Trabajo, se emitirá pronunciamiento al efecto, señalando que de todas formas tal precepto no resulta aplicable por lo que se dirá a continuación.

DÉCIMO TERCERO: Que resulta necesario considerar que la acción interpuesta por el demandante es aquella que está prevista en el artículo 171 del Código del Trabajo, conocida en doctrina como despido indirecto, pues imputa a su empleador haber incurrido en las causales de terminación del contrato de trabajo de los $\mathrm{N}^{\mathrm{os}} 1,5$ y 7 del artículo 160 del mismo texto legal. En otros términos, es el trabajador quien decide finalizar la relación laboral habida con el demandado por alguna de las causales señaladas.

DÉCIMO CUARTO: Que el artículo 162 del Código del ramo, que en sus incisos quinto, sexto y séptimo, prescribe: "Para proceder al despido de un trabajador por alguna de las causales a que se refieren los incisos precedentes o el artículo anterior, el empleador le deberá informar por escrito el estado de pago de las cotizaciones previsionales devengadas hasta el último día del mes anterior al del despido, adjuntando los comprobantes que los justifiquen. Si el empleador no hubiere efectuado el integro de dichas cotizaciones previsionales al momento del despido, éste no producirá el efecto de poner término al contrato de trabajo.

Con todo, el empleador podrá convalidar el despido mediante el pago de las imposiciones morosas del trabajador, lo que comunicará a éste mediante carta certificada acompañada de la documentación emitida por las instituciones previsionales correspondientes, 
en que conste la recepción de dicho pago. Sin perjuicio de lo anterior, el empleador deberá pagar al trabajador las remuneraciones y demás prestaciones consignadas en el contrato de trabajo durante el periodo comprendido entre la fecha del despido y la fecha de envío o entrega de la referida comunicación al trabajador".

DÉCIMO QUINTO: Que del tenor literal de la norma antes transcrita, se puede advertir que la sanción pecuniaria impuesta al empleador, de mantener la remuneración a sus dependientes, exige que dicho sujeto haya tenido una conducta activa en el despido de sus trabajadores, es decir, que haya sido el empleador quien por decisión unilateral haya puesto término a la relación laboral, lo que no se da en la especie, pues, en este caso, es el dependiente quien puso término a ella, invocando causales de caducidad en las que incurrió el empleador.

DÉCIMO SEXTO: Que de lo antes reflexionado aparece que no correspondía acoger la petición del demandante, consistente en el pago de las remuneraciones a contar de la fecha del término de sus servicios hasta que el empleador acreditara el pago de las cotizaciones, por no concurrir los presupuestos legales para ello.

DÉCIMO SÉPTIMO: Que conforme a lo razonado, la sentencia que se impugna vulneró las disposiciones de los artículos $1^{\circ}$, 162, y 171 del Código del Trabajo; y 71 y 72 del Estatuto docente, al hacer aplicable a la actora una causal de término de la relación laboral no prevista en la ley a su respecto dando además cabida a la nulidad del despido en un caso no establecido en la Ley.

DÉCIMO OCTAVO: Que, en consecuencia y además, debe entenderse unificada la jurisprudencia en el sentido que el artículo 171 del Código del Trabajo no resulta aplicable a los profesionales de la Educación regidos por el estatuto docente; que éstos no tienen derecho a indemnizaciones por el término de su contrato de trabajo sino cuando expresamente el mencionado estatuto lo contemple; y que la sanción del artículo 162 inciso séptimo del Código Laboral, de haber sido aplicable este cuerpo de normas igualmente no rige cuando, como en la especie, es el trabajador quien pone término a la relación laboral, de conformidad con lo dispuesto en el artículo 171 del Código citado.

Por estas consideraciones y visto, además, lo dispuesto en los artículos 474, 477, 479, 481 y 482 del Código del Trabajo, se acoge, sin costas, el recurso de nulidad deducido por la demandada, contra la sentencia de cinco de julio de dos mil once, escrita a fojas 66 y siguientes.

Redacción a cargo de la abogada integrante señora Virginia Cecily Halpern Montecino.

REGÍSTRESE.

No 10266-2011.

Pronunciado por la Cuarta Sala de la Corte Suprema integrada por los Ministros señora Gabriela Pérez P, señora Rosa Egnem S., Ministro Suplente señor Juan Escobar Z., y los Abogados Integrantes señores Ricardo Peralta V., y Virginia Halpern M. Santiago tres de agosto de dos mil doce.

Autoriza la Ministra de Fe de la Excma. Corte Suprema.

En Santiago, a tres de agosto de dos mil doce, notifiqué en Secretaria por el Estado Diario la resolución precedente.

Santiago, tres de agosto de dos mil doce. 


\section{VISTOS:}

Se mantiene la sentencia de la instancia de cinco de julio de dos mil once los considerandos primero a duodécimo y el párrafo primero del considerando décimo octavo.

Y teniendo, además, presente:

$1^{\circ} \quad$ Los considerandos primero a undécimo de la sentencia de nulidad que antecede, los que se tienen por expresamente reproducidos.

$2^{\circ} \quad$ El razonamiento décimo quinto de la sentencia dictada por la Corte de Apelaciones de San Miguel, no afecto al recurso de unificación de jurisprudencia.

$3^{\circ}$ Que conforme a lo razonado, la demanda deberá ser rechazada en cuanto a la solicitud de que se declare justificado el auto despido de la actora, la nulidad del mismo por no pago de cotizaciones previsionales y la indemnización prevista en el inciso tercero del artículo 489 del Código del Trabajo por improcedente.

Y de conformidad, además, con lo dispuesto en los artículos 162, 171, 425, 432, 456, 458, 459 y 489 del Código del Trabajo, se declara:

1. - Que se acoge la demanda solo en cuanto se condena al empleador a enterar en Fonasa la cotización de salud correspondiente al mes de noviembre de 2008.

2. - Que se rechaza en lo demás la referida demanda.

3. - Que no se condena en costas de la causa a la parte demandada por no haber sido totalmente vencida.

Redacción a cargo de la Abogado Integrante señora Virginia Cecily Halpern Montecino. REGÍSTRESE Y DEVUÉLVASE.

No 10266-2011

Pronunciado por la Cuarta Sala de la Corte Suprema integrada por los Ministros señora Gabriela Pérez P, señora Rosa Egnem S., Ministro Suplente señor Juan Escobar Z., y los Abogados Integrantes señores Ricardo Peralta V., y Virginia Halpern M. Santiago tres de agosto de dos mil doce.

Autoriza la Ministra de Fe de la Excma. Corte Suprema.

En Santiago, a tres de agosto de dos mil doce, notifiqué en Secretaria por el Estado Diario la resolución precedente.

\section{COMENTARIO}

La sentencia de reemplazo expuesta anteriormente es dictada por la Excma. Corte Suprema con la finalidad de unificar la jurisprudencia relativa a la aplicación supletoria del Código del Trabajo a los profesionales de la educación o docentes que presten sus servicios para una municipalidad o una corporación municipal. Asimismo, se refiere a la procedencia de la sanción del artículo 162 del Código del Trabajo en un caso de autodespido.

No obstante lo anterior, la materia que provoca mayor interés en el presente comentario, es respecto a la aplicación supletoria que se realiza de la normativa laboral a los docentes 
antes mencionados. Ello, pues la aplicación de la sanción del artículo 162 en caso de autodespido, es una cuestión ampliamente zanjada por la doctrina y jurisprudencia nacional.

Así las cosas, el fallo en comento dispone de manera acertada que el artículo 171 del Código del Trabajo no resulta aplicable a los profesionales de la educación regidos por el Estatuto Docente y que estos no tienen derecho a indemnización alguna al término de su contrato de trabajo, salvo cuando expresamente se haya contemplado.

\section{DEL ESTATUTO APLICABLE A LOS PROFESIONALES DE LA EDUCACIÓN}

La Ley No 19.070, o también conocida como Estatuto Docente ${ }^{1}$, se aplica a los profesionales de la educación que presten servicios en los establecimientos de educación básica y media, de administración municipal o particular reconocida oficialmente. Sin embargo, la regulación difiere sustancialmente dependiendo de la clase de docente al cual se aplica. Así, mientras el estatuto regula de forma detallada y extensa las funciones de los docentes municipalizados (forma de ingreso a la carrera docente, derechos y obligaciones, jornada de trabajo, terminación de la relación laboral, entre otras), en el caso de los docentes adscritos al sector particular señala que sus relaciones se regirán por las normas del Código del Trabajo en todo lo no expresamente establecido en el Título IV del Estatuto.

Considerando lo expresado, cualquier controversia que surja entre los docentes dependientes del municipio (o de una corporación municipal), deberá ser resuelta en virtud de lo contemplado en el Estatuto Docente. Sin embargo, la cuestión controvertida en el fallo que se comenta, dice relación con la posibilidad que un docente utilice la figura del autodespido $y$, si en ese caso, proceden las indemnizaciones que contempla la normativa laboral general; materias que no se encuentran reguladas de manera expresa en el mencionado estatuto.

En dicho escenario surge para el sentenciador lo dispuesto en el artículo 71 del Estatuto Docente y $^{10}$ del Código del Trabajo ${ }^{3}$, los cuales prescriben la aplicación supletoria de la normativa laboral. Ante eso, el juez necesariamente deberá realizar el siguiente análisis: primero determinar si la materia demandada se encuentra regulada en la norma (Estatuto Docente), y si no se encuentra normada, deberá examinar si con la aplicación de la normativa laboral general sus soluciones no resultan contrarias a lo contenido en el estatuto.

\footnotetext{
DFL No 1 de 10.09.1996. Fija texto refundido, coordinado y sistematizado de la Ley No 19.070 que aprobó el Estatuto de los Profesionales de la Educación, y de las leyes que la complementan y modifican.

2 Artículo 71 (inciso primero): Los profesionales de la educación que se desempeñan en el sector municipal se regirán por las normas de este Estatuto de la profesión docente, y supletoriamente por las del Código del Trabajo y sus leyes complementarias.

3 Artículo 1 (incisos segundo y tercero): Estas normas no se aplicarán, sin embargo, a los funcionarios de la Administración del Estado, centralizada y descentralizada, del Congreso Nacional y del Poder Judicial, ni a los trabajadores de las empresas o instituciones del Estado o de aquellas en que éste tenga aportes, participación o representación, siempre que dichos funcionarios o trabajadores se encuentren sometidos por ley a un estatuto especial.

Con todo, los trabajadores de las entidades señaladas en el inciso precedente se sujetarán a las normas de este Código en los aspectos o materias no regulados en sus respectivos estatutos, siempre que ellas no fueren contrarias a estos últimos.
} 


\section{DEL AUTODESPIDO Y LA INDEMNIZACIÓN POR AÑOS DE SERVICIO EN EL ESTATUTO DOCENTE}

Antes de analizar la procedencia del autodespido en el Estatuto Docente, resulta preciso señalar en qué consiste dicha figura. Así, la doctrina ha señalado que este "es el término del contrato de trabajo, decidido por el trabajador, observando el procedimiento que la ley señala, motivado porque el empleador incurrió en causal de caducidad de contrato que le es imputable, lo que le da derecho al trabajador para que el tribunal ordene el pago de la indemnización sustitutiva del aviso previo y de la de años de servicio más los recargos legales"4.

El fallo que se comenta surge en virtud de la demanda de tutela de derechos fundamentales con ocasión del despido indirecto incoada por la Sra. Rosita Peralta. El tribunal de primera instancia da lugar a la aplicación de esta figura, lo que es ratificado por la Iltma. Corte de Apelaciones. Posteriormente la Excma. Corte Suprema, en recurso de unificación de jurisprudencia, sostiene que en el caso de los profesionales de la educación municipalizada no procede la aplicación del autodespido ni indemnización alguna.

El sentenciador arriba a dicha conclusión, ya que en el caso de estos docentes el artículo 72 del Estatuto ${ }^{5}$ contempla de manera expresa las causales de terminación de la relación laboral, dentro de las cuales no se considera el autodespido (el mencionado artículo señala que "los profesionales de una dotación docente del sector municipal, dejarán de pertenecer a ella, solamente, por las siguientes causales..."). Asimismo, tampoco contempla el pago de una indemnización de forma genérica, pues el artículo 73 reconoce el pago de una indemnización de cargo del empleador, solo cuando la relación haya concluido por la supresión de las horas que sirva el docente en el establecimiento educacional (artículo 72 letra j del estatuto).

De lo antes expresado, se infiere que lo razonado por la Excma. Corte Suprema resulta adecuado, pues ante la existencia de una norma expresa relativa a las causales de término de la relación laboral y respecto a los casos en los que procede el pago de una indemnización por los años de servicio ${ }^{6}$, no procede la aplicación supletoria del Código del Trabajo.

\section{DE LA INTERPRETACIÓN DE LA NORMATIVA LABORAL Y DEL ARTÍCULO 23 DEL CÓDIGO CIVIL}

Ahora bien, pese a la mencionada rectitud del fallo, existen ciertos tópicos que es necesario hacer presente. Ello, sobre todo teniendo en cuenta que el criterio expuesto en esta

\footnotetext{
4 ThaYer A., William y NovoA F., Patricio. Manual de Derecho del Trabajo. Tomo IV. Santiago, Chile: Editorial Jurídica de Chile, 2010, p. 56.

5 Este artículo contempla las siguientes causales de terminación de la relación laboral: renuncia voluntaria; falta de probidad o conducta inmoral; incumplimiento grave de las obligaciones que impone su función; término del período por el cual se efectuó el contrato; obtención de jubilación, pensión o renta vitalicia; fallecimiento; por calificación en lista de demérito por dos años consecutivos; salud irrecuperable; por pérdida sobreviniente de algunos de los requisitos de incorporación a una dotación docente; supresión de las horas que sirvan; renuncia anticipada en los términos del artículo 70 del Estatuto Docente y por disposición del sostenedor en el caso de docentes mal evaluados.

6 Este razonamiento es también coherente con lo expresado por la Contraloría General de la República (Dictamen No $57.926 / 2009)$.
} 
sentencia de unificación, ha sido utilizado por la Excma. Corte Suprema de forma reiterada en los autos No $10.218-2011^{7}$, No 7.154-2010 ${ }^{8}$, No 5.618-2010 , entre otros.

En este sentido, es necesario precisar que uno de los principios fundamentales del derecho sustantivo laboral es el principio protector, el cual se expresa en tres aspectos diferentes: la regla del in dubio pro operario (interpretación más favorable al trabajador); la regla de la norma más favorable y la regla de la condición más beneficiosa para el trabajador ${ }^{10}$. Así las cosas, el juez laboral deberá aplicar este principio al momento de conocer de una determinada materia e interpretar la normativa que corresponda.

Sin embargo, la aplicación de este principio no siempre resulta procedente. Esto resulta evidente en el caso en comento, pues pese a lo injusto u "odioso" que aquello pudiese resultar; dicha injusticia no se puede tomar en cuenta para ampliar o restringir la interpretación de una norma, tal como lo manifiesta artículo 23 del Código Civil.

Ante esto, ¿a qué hacemos alusión cuando se menciona que lo odioso de una disposición no puede considerarse al momento de interpretar la ley? Simple, el fallo que ha sido comentado, surge de una acción de tutela impetrada por una docente que sirve al sector municipal. Si se analizan los hechos de la demanda y la sentencia de primera instancia ${ }^{11}$, se

\footnotetext{
Navarro con Corporación Municipal de Desarrollo Social de Colina. En su considerando octavo sostiene "que el mencionado Estatuto Docente no contempla en sus disposiciones la transformación en indefinida de las sucesivas contrataciones a plazo fijo, regulando pura y simplemente el vencimiento del plazo, de modo que no es procedente recurrir supletoriamente, aunque exista remisión expresa del Estatuto Docente a las normas del Código del Trabajo, en la medida en que tal como la norma lo indica es "supletoria", es decir, en el evento de no existir regulación alguna, pero no para los efectos de complementarla, que es lo que entiende el recurrente, al sostener que la materia no se encuentra "suficientemente" reglada en el Estatuto Docente".

8 Orellana con Ilustre Municipalidad de El Monte. En su considerando décimo sexto señala "que las normas del Código Laboral relativas al contrato de trabajo, al aviso de la terminación del contrato laboral, a la indemnización por años de servicios que encierran sus artículos 7, 162 y 163, no pueden recibir aplicación supletoria en el caso de el (sic) actor, ya que, según se ha anotado, el Estatuto Docente establece su propia regulación en torno a las calidades funcionarias en que pueden pertenecer a una dotación docente municipal, a las causales de expiración en los cargos de titulares y de contratados y a los beneficios a que puede dar lugar el cese de funciones y sus disposiciones rigen con preferencia a quienes integran una dotación docente, excluyendo el imperio del derecho laboral común en esos asuntos, al tenor de lo preceptuado tanto en el artículo 71 del mismo Estatuto Docente como en los incisos segundo y tercero del artículo 1 del Código del Trabajo, sin perjuicio de considerarse además el artículo 13 del Código Civil”.

9 Flores con Corporación Municipal de San Miguel. En su considerando décimo señala que "las normas del Código Laboral relativas al contrato de trabajo, a la presunción establecida en el artículo $9^{\circ}$, a la transformación en indefinidos de los contratos a plazo fijo, entre otras, no pueden recibir aplicación supletoria en el caso del actor, ya que, según se ha anotado, el Estatuto Docente establece su propia regulación en torno a las calidades funcionarias en que pueden pertenecer a una dotación docente municipal, a las causales de expiración en los cargos de titulares y de contratados y a los beneficios a que puede dar lugar el cese de funciones y sus disposiciones rigen con preferencia a quienes integran una dotación docente, excluyendo el imperio del derecho laboral común en esos asuntos, al tenor de lo preceptuado tanto en el artículo 71 del mismo Estatuto Docente como en los incisos segundo y tercero del artículo 1 del Código del Trabajo, sin perjuicio de considerarse además el artículo 13 del Código Civil”.

10 Cfr., Lanata F., Gabriela. Contrato Individual de Trabajo. -4a edición-. Santiago, Chile: Editorial LegalPublishing, 2010, pp. $47-48$.

11 Los hechos relatados en la demanda son los siguientes: La Sra. Rosita Peralta demanda a la Corporación Municipal de Educación, Salud y atención de menores de Puente Alto, en atención al acoso moral laboral y hostigamiento de parte de la Directora del Colegio en el cual ella se desempeñaba. En el libelo expresa una serie de conductas constitutivas de acoso: ridiculización ante compañeros de trabajo, aislamiento del resto del personal, entre otras cuestiones. Asimismo, señala que pese a la denuncia realizada ante la Dirección del Trabajo, el acoso continúa e incluso aumenta.
} 
aprecia que contra la demandante existieron actuaciones que responden a acoso moral laboral ${ }^{12}$, pues la directora del establecimiento en el cual trabajaba ejercía en su contra malos tratos y hostigamientos de manera reiterada.

No obstante lo anterior, esta docente (a diferencia de lo que ocurre con una docente que preste servicios al sector particular) en base a la normativa vigente, no tiene oportunidad de colocar fin a su relación laboral mediante el artículo 171 del Código del Trabajo; salvo que decida renunciar y perder las bonificaciones o indemnizaciones que pudiese llegar a tener ${ }^{13}$. Es más, solo tiene la posibilidad de solicitar la respectiva investigación sumaria en contra del o los acosadores o realizar la respectiva denuncia administrativa o judicial, con los posteriores apremios (multas) que de ello pueda resultar. Pero ¿qué pasa si las conductas aún así continúan? El docente se verá forzado a continuar en su trabajo con los efectos sicológicos que ello conlleva.

En este aspecto, resulta forzoso mencionar que en el caso del Estatuto Docente, no se incorporó una norma que prescriba de forma expresa la prohibición del acoso laboral, como en el caso del Estatuto Administrativo y del Estatuto Administrativo para Funcionarios Municipales (en virtud de la Ley $\mathrm{N}^{\circ}$ 20.607). Por ende, para los docentes municipales, solo queda la aplicación supletoria de las normas del Código del Trabajo, con las falencias que se expresan en el presente comentario.

Así las cosas, volvemos a lo señalado en el artículo 23 del Código Civil. Ello, pues a diferencia de lo que sucede con otros trabajadores e incluso con los docentes contratados por el sector particular, los docentes "municipalizados" ven mermados sus derechos en situaciones como estas, precisamente porque la interpretación de la norma se debe realizar con prescindencia de lo favorable u odioso de sus disposiciones ${ }^{14}$. Así, mientras los otros docen-

\footnotetext{
Por su parte, la sentencia de primera instancia (T-11-2011 del Juzgado de Letras del Trabajo de Puente Alto), sostiene en su considerando décimo cuarto, lo que sigue: "Que en mérito de la prueba rendida en autos, es decir, prueba documental, y testimonial de ambas partes, y oficios, ya detallada en los considerandos sexto, séptimo, octavo, noveno, décimo, y undécimo; prueba que ponderada, es posible tener por acreditados los siguientes hechos: 1.- Que la demandante en reiteradas ocasiones sufrió malos tratos por parte de la directora del establecimiento Oscar Bonilla. 2.- Que la actora le puso término a la relación laboral a raíz de los innumerables malos tratos, humillaciones y otros, ello con fecha 16 de marzo de 2011. 3.- Que al término de la relación laboral no se le pagó ninguna prestación a la demandante. 4.- La jornada laboral de la demandante de autos era de 44 horas semanales, que al querer trasladarla se le dejaría 3 horas semanales. 5.- Que a raíz de los diversos malos tratos ocasionados en contra de la actora, ésta se encontraba subsumida en una grave depresión, por lo que tuvo que tener un tratamiento médico prolongado".

12 El artículo 2 del Código del Trabajo sostiene que el acoso laboral consiste en "toda conducta que constituya agresión u hostigamiento reiterados, ejercida por el empleador o por uno o más trabajadores, en contra de otro u otros trabajadores, por cualquier medio, y que tenga como resultado para el o los afectados su menoscabo, maltrato o humillación, o bien que amenace o perjudique su situación laboral o sus oportunidades en el empleo". Por otra parte, la doctrina laboral ha entendido que "el acoso moral comprende los hostigamientos periódicos realizados en el lugar de trabajo con la finalidad de humillar y marginar a un determinado trabajador, provocando, incluso su renuncia, muchas veces acompañada de daños a la salud como la depresión, estrés o ansiedad, además de transtornos psicomáticos”. Gamonal C., Sergio y Guidi M., Caterina. Manual del Contrato de Trabajo. Santiago, Chile: Editorial LegalPublishing, Santiago, 2010, pp. 221.

13 En este punto es preciso señalar que los docentes municipalizados pueden obtener bonificaciones cuando la relación laboral termina (por disposición del sostenedor en el caso de docentes mal evaluados o por calificación en lista de demérito por dos años consecutivos) e incluso se han dictado leyes como la 20.501 que entregan bonificaciones en caso de retiro voluntario; las que evidentemente el docente perdería en el caso de verse forzado a renunciar ante conductas de acoso laboral.

14 Sin embargo, en este aspecto no solo entra en juego esta disposición, sino también el principio de legalidad que impera en el derecho público (Estatuto Docente).
} 
tes (sector particular) tienen la posibilidad de aplicar casi con plenitud las normas laborales, en este caso, sus posibilidades están completamente restringidas.

Tan evidente resulta esta precariedad, que en el caso en comento se realizaron las denuncias respectivas ante la Inspección del Trabajo, sin que ello implicara una disminución de las conductas constitutivas de acoso laboral; lo que en definitiva llevó a que la docente "intentara" terminar su relación laboral con la figura del autodespido con el resultado ya expresado.

Lo expuesto deja de manifiesto que en ciertas materias, pese a los principios rectores del derecho del trabajo, debe primar necesariamente lo establecido en la norma, aun cuando ello implique serías injusticias ${ }^{15}$ o desprotección en el ámbito laboral. Asimismo, deja en evidencia la precariedad del contrato laboral de estos docentes ${ }^{16}$, lo que evidentemente no solo responde a la interpretación del sentenciador sino también a la intención del legislador al momento de dictar el Estatuto de los profesionales de la educación.

\footnotetext{
15 En este sentido resulta esencial traer a colación la sentencia de la Excma. Corte Suprema en el rol de ingreso No 2.2362004, en la cual se aplica lo prescrito en el artículo 159 No 4 del Código del Trabajo a docentes que ejercen sus funciones en el sector particular. Por otra parte, se encuentra la ya citada sentencia en los autos No 7.154-2010 en la cual a un docente municipal a contrata por 7 años, no se le aplica el artículo 159 No 4 en virtud de la aplicación supletoria del Código del Trabajo.

16 Vid., respecto a esta materia: QUIROZ D., Felipe. "La precariedad del contrato laboral de los profesionales de la educación en el sector municipal”, en: Revista Estudios Laborales. Santiago, Chile: LegalPublishing y Sociedad Chilena de Derecho del Trabajo y de la Seguridad Social, No 6, 2012, pp. 93-112.
} 